Copyright by the American Society of Agricultural and Biological Engineers. Bosch, D. J.; Ogg, C.; Osei, E.; Stoecker, A. L., "Economic models for TMDL assessment and implementation," Transactions of the ASABE. Vol. 49(4): 1051-1065. (doi: 10.13031/2013.21744) @2006

\title{
ECONOMIC MODELS FOR TMDL ASSESSMENT AND IMPLEMENTATION
}

\author{
D. J. Bosch, C. Ogg, E. Osei，A. L. Stoecker
}

\begin{abstract}
The TMDL assessment and implementation process is designed to achieve designated uses for water bodies, which are set by states based on criteria including perceived costs and benefits. Setting water quality goals based on designated uses and plans to achieve these goals have important implications for public welfare. Both treatment and damage costs should be considered in simultaneously determining the desired water quality goal and allocating pollution reductions among sources to achieve that goal. Assessing and implementing TMDL plans are complicated by uncertainties about pollution damages and stakeholder responses. Economic optimization or simulation models linked to water quality models allow water quality impacts and costs of TMDL standards to be assessed. Higher water quality thresholds may be reserved for watersheds with higher estimated benefits. Costs of achieving standards can be reduced by targeting reductions at pollution sources with the lowest costs of achieving reductions. Trading programs can help achieve efficient targeting of pollution reductions while distributing costs equitably. The effectiveness of economic models to assist in setting water quality goals and in TMDL program planning and implementation can be improved by using economic models to analyze costs and benefits of water quality improvements and to assist with pollution targeting and trading programs to minimize costs of reducing pollution. Multi-media impacts of pollution should be included within economic and environmental water quality models. Given uncertainties about benefits and costs of achieving TMDL standards, policymakers and program managers need to collect more data on stakeholder responses to TMDL programs as well as better monitoring data on pollutant levels and functioning of aquatic systems.
\end{abstract}

Keywords. Cost minimization, Economics, Efficiency, Equity, Optimization models, Policy, Pollution allocation, Simulation models, TMDL, Uncertainty.

$\mathrm{T}$ he Total Maximum Daily Load (TMDL) assessment and implementation process is designed to achieve designated uses for water bodies, which are set by states based on criteria including perceived costs and benefits. Given the large number of TMDLs being developed as a result of recent court actions (Keplinger, 2003), the process of setting goals for water quality improvement and devising plans to achieve these goals will have important implications for public welfare (Muñoz-Carpena et al., 2006). The term TMDL is used interchangeably to mean (1) the process for implementing state water quality standards, and (2) the numerical quantity indicating the maximum load of pollutants to receiving water bodies from point and nonpoint sources that will not violate the state water quality standards (USEPA, 1999; National Research Council, 2001). Properly designed and implemented TMDLs reduce loadings and allow water bodies to meet their designated

Submitted for review in February 2006 as manuscript number SW 6357; approved for publication by the Soil \& Water Division of ASABE in July 2006.

The authors are Darrell J. Bosch, Professor, Department of Agricultural and Applied Economics, Virginia Tech, Blacksburg, Virginia Clayton Ogg, Economist, Environmental Protection Agency, Washington, D.C.; Edward Osei, Senior Research Economist, Texas Institute for Applied Environmental Research, Tarleton State University, Stephenville, Texas; and Arthur L. Stoecker, Associate Professor, Department of Agricultural Economics, Oklahoma State University, Stillwater, Oklahoma. Corresponding author: Darrell J. Bosch, Department of Agricultural and Applied Economics, Virginia Tech, Blacksburg, VA 24061; phone: 540-231-5265; e-mail: bosch@vt.edu. uses, thus enhancing resource values and contributing to the economic productivity of a region. Improved water quality may make water bodies more suitable for a variety of uses, including recreation, aesthetics, household consumption, agriculture, and sustaining diverse aquatic ecosystems. Simultaneously, the costs of making the water suitable for its designated use (for example, drinking water) may be reduced.

Restoring the uses of a water body through a TMDL plan may also involve significant costs. Costs of designing and implementing a TMDL plan include direct costs of installing new practices or treatment programs to reduce pollution loads and indirect or opportunity costs of forgoing profitable production opportunities. In addition, transaction costs are incurred for informing stakeholders about their pollution reduction responsibilities, contracting with stakeholders to reduce pollution, and enforcing pollution reduction activities by stakeholders (Krier and Montgomery, 1973). Costs of implementing TMDLs may be distributed among point and nonpoint pollution sources as well as other stakeholders (such as taxpayers) who may not contribute directly to pollution in the watershed.

Although goal-setting and planning take place within an institutional context, which constrains the way goals can be achieved, economic analysis can play a pivotal role throughout the TMDL process (USEPA, 1999), informing each specific step that must be followed in identifying impaired watersheds and establishing and implementing TMDLs. Water quality standards are set for water bodies based on designated uses and on numeric and narrative criteria that 
"will reflect a social consensus made in consideration of the current condition of the watershed, its predisturbance condition, the advantages derived from a certain designated use, and the costs of achieving the designated use" (National Research Council, 2001, p. 24). States formally list water bodies that remain impaired (even after implementation of other water quality programs) by one or more pollutants and that require TMDL plan elements. The TMDL Water Quality Management plan then includes a listing of pollutant sources, an estimate of the reduction in pollution load that is required to achieve the designated use, an allocation of load reductions to different sources, and a plan identifying practices for implementing the load reductions. Public stakeholder involvement is required in setting designated uses for water bodies and subsequent TMDL plan development. Cost and benefit information is needed to guide each step of this process, including the above identification of uses, allocation of pollution loads, and identification of practices to achieve load reductions. Finally, an important part of the process is the implementation of the actions envisioned in the TMDL plan, tracking of progress, and eventual delisting of the water body when goals are accomplished. Implementation can include limitations on emissions by point sources beyond technology-based effluent standards as well as prescribed Best Management Practices (BMPs) for nonpoint sources (National Research Council, 2001). TMDL planning and implementation do not involve regulatory controls on nonpoint sources. States may choose to implement regulations on nonpoint sources but for the most part have not done so.

The setting of water quality goals and design and implementation of TMDL plans to achieve goals can be improved by recognizing that watershed stakeholders may have diverse objectives related to improving water quality. Stakeholders may differ as to what the designated use of the water body should be, which affects the required amount of water quality improvement and the setting of the TMDL. After a designated use has been selected based on political consensus, the goal implicit in the TMDL process is to improve water quality in water bodies so that they can better meet their designated uses. Another goal is to minimize the cost to stakeholders of achieving the desired level of water quality that supports the designated use. Equitable distribution among stakeholders of the costs of achieving TMDL goals may be an important consideration. Stakeholders with a strong interest in maintaining watershed water quality may desire to reduce risks of exceeding TMDL targets for a pollutant. A plan that has low annual or seasonal variability in pollution loads may be preferred to a less expensive plan with greater variability in pollution loads. Alternatively, stakeholders may desire to guard against risks of large and unexpected increases in the costs of attaining TMDL targets. The challenge confronting policymakers is to develop and implement plans that achieve an appropriate balance among diverse stakeholder goals.

Economic models and analysis provide a framework for achieving an appropriate balance of diverse stakeholder goals with respect to the TMDL process. The institutional requirements of the TMDL process can be incorporated into economic models to ensure that workable goals and plans are developed. In the next section, we discuss the role of economics in setting water quality standards and associated TMDLs and in planning and implementing Water Quality
Management plans for TMDLs. We analyze the economic models that are or can be used in the TMDL development and implementation process, including regional or statewide models with site-specific detail. A following section discusses ways of overcoming barriers to implementing TMDL policies. A final section summarizes findings of the study and offers recommendations for improving the ability of economic models to assist with design and implementation of TMDL programs.

\section{ROLE OF ECONOMICS IN TMDL ASSESSMENT AND IMPLEMENTATION} Role OF ECONOMIC Models

The role of economic models in TMDL development and implementation is increasing, particularly in recent years as more stakeholders, researchers, and public officials recognize the crucial importance of cost-effective and equitable load allocations. Economic models play an indispensable role in dealing with the two primary issues that arise in TMDL development and implementation: efficiency and equity (Keplinger, 2003). In addition, economic models are vital tools for assessing the benefits, challenges, and progress of TMDL implementation.

Economic models provide estimates of economic indicators, which generally fall into two categories: costs and benefits. Costs of TMDL implementation include, but are not limited to, the explicit and implicit expenses incurred by landowners and other stakeholders who implement measures to reduce pollutant loads in response to the TMDL. Explicit expenses include expenditures by farmers, localities, and other entities to control pollution (e.g., installing a conservation buffer). Implicit expenditures, also labeled opportunity costs, include the income given up when pollution control practices are followed (e.g., planting less profitable crops in a rotation in order to reduce runoff). Economic analyses of TMDL development also consider transactions costs (Krier and Montgomery, 1973). Transactions costs include costs of contracting reduction measures with stakeholders and monitoring and enforcing reduction measures.

Benefits of TMDL implementation include implicit and explicit revenues or returns to landowners and other stakeholders as well as improvements in environmental indicators, which may have benefits to the regional economy. For example, improved water quality in a watershed may contribute to a region's quality of life and enhance its ability to attract new residents and businesses. Various kinds of economic models are used to estimate costs and benefits in support of TMDL development and implementation, as well as other environmental policies. The following conceptual framework illustrates the close linkage between costs and benefits in setting designated uses for water bodies and devising and implementing TMDL plans to achieve those uses.

\section{Conceptual Framework}

The method of choosing water quality standards for water bodies based on designated uses to maximize national or social net benefits has been known since the 1970s (Freeman et al., 1973). A review of the basic theory is important because the real-world approach to setting water quality standards with associated TMDLs and the allocation of waste 
loads is not consistent with the maximization of net social benefits. Freeman et al. (1973) showed and current resource economics textbooks (Tietenberg, 2003) reiterate that general welfare can be maximized by minimizing the sum of total pollution abatement cost and total environmental damage cost. The logic of the approach is that both the value of damages caused by pollution and the money spent to prevent or remove pollution are wastes to be avoided or minimized. The reason the latter is a waste is that no society would logically allocate resources to pollution treatment except to avoid or reduce the damages from pollution. Resources should be devoted to pollution abatement as long as the value of pollution damages avoided is greater than the cost of treating pollution to avoid those damages.

The basic linear two-step process (with no feedback loop) of setting a TMDL by first determining the maximum pollution load that meets designated uses and secondly allocating the waste load among sources is flawed in that it prevents the determination of the most cost-effective TMDL and the most efficient allocation of the waste load among sources. For this reason, the current two-step process cannot in all cases guarantee that as a whole the stakeholders affected by the implementation of a particular TMDL are better off after the TMDL is implemented than before it was implemented. A simplified example is provided below, which is designed to (1) illustrate the flaw in the two-step procedure of first setting the TMDL and then allocating the waste load, and (2) show that the common practice of allocating a given waste load proportionately among sources may lead to more costly pollution treatment than necessary. The purpose of the static and deterministic example is to point out that to be efficient the process of setting the TMDL, the allocation of the waste load, and the implementation of the plan to achieve the TMDL goal are parts of a system that require a simultaneous or iterative solution. In the example, we assume that the pollutant dissipates each year and does not accumulate from one year to the next.

Assume a watershed has two sources of pollution (each emitting 100 tons per year but with different abatement costs) that cause environmental damage. These may be either point or nonpoint sources. For each source $i$, the total current emitted pollution $\left(E P_{i}\right)$ is equal to the pollution removed or abated $\left(A_{i}\right)$ and the pollution remaining $\left(P_{i}\right)$. The social objective is to minimize the sum of damage costs from pollution plus the cost of abating that damage by reducing pollution. The benefits of pollution abatement are conceptualized as the negative of environmental damage costs, because these costs can be avoided by abating pollution. This social objective is realized subject to the constraint that total emitted pollution is either removed or remains in the environment. The social objective can be expressed as a constrained Lagrangian function that minimizes the sum of the cost of damage from pollution plus the cost of abating that damage subject to the constraint on total emitted pollution:

$$
\begin{aligned}
& \operatorname{Min} W(P)=a_{1} A_{1}^{2}+a_{2} A_{2}^{2}+d\left(P_{1}+P_{2}\right)^{2} \\
& +\lambda_{1}\left(E P_{1}-P_{1}-A_{1}\right)+\lambda_{2}\left(E P_{2}-P_{2}-A_{2}\right)
\end{aligned}
$$

where $W(P)$ is a pollutant-dependent social cost function, $a_{i}$ $A_{i}{ }^{2}$ is the total abatement or treatment cost at source $i$ for removing $A_{i}$ units of pollution, and $d\left(\sum P_{i}\right)^{2}$ is the monetary value of environmental damage caused by the remaining pollution from each source $i$. The Lagrangian multiplier $\left(\lambda_{i}\right)$ measures the sensitivity of social cost to changes in the pollution constraint. An increase of the pollution constraint $E P_{i}$ by one unit raises the social cost by $\lambda_{i}$ units. The quadratic form for abatement cost at each source is chosen for simplicity. It also reflects the general view that as one moves from primary to secondary to tertiary methods to remove more of a pollutant, the cost per unit of pollutant removed increases at an increasing rate. Similarly, the modeling of damages as a quadratic function is chosen for simplicity, but it conveys the general view that the amount of damage caused by a pollutant increases at an increasing rate with the amount of pollution.

The social objective is achieved by minimizing the sum of pollution abatement costs and environmental damage costs. By taking the first partial derivatives of the Lagrangian with respect to the $A_{i}$ units of pollution, the first-order conditions for minimizing social cost with respect to $A_{i}$ and $\lambda_{i}$ are:

$$
\begin{gathered}
\partial W / \partial A_{1}=2 a_{1} A_{1}-\lambda_{1}=0 \\
\partial W / \partial A_{2}=2 a_{2} A_{2}-\lambda_{2}=0
\end{gathered}
$$

Social cost is minimized where the marginal abatement cost (MAC) of treating source $1\left(2 a_{1} A_{1}\right)$ minus the marginal cost of raising the constraint on total pollution at source 1 by one unit $\left(\lambda_{1}\right)$ equals zero. The same relationship holds for source 2 .

First-order conditions with respect to $P_{i}$ are:

$$
\begin{gathered}
\partial W / \partial P_{1}=2 d\left(P_{1}+P_{2}\right)-\lambda_{1}=0 \\
\partial W / \partial P_{2}=2 d\left(P_{1}+P_{2}\right)-\lambda_{2}=0
\end{gathered}
$$

Marginal damage cost (MDC) from pollution at source 1, $2 d\left(P_{1}+P_{2}\right)$, minus the marginal cost of raising the constraint on total pollution at source $1\left(\lambda_{1}\right)$ is equal to zero. The same relationship is true for source 2 . Finally, first-order conditions with respect to $\lambda_{i}$ are the constraints on total pollution emitted from each source:

$$
\begin{gathered}
\partial W / \partial \lambda_{1}=E P_{1}-P_{1}-A_{1}=0 \\
\partial W / \partial \lambda_{2}=E P_{2}-P_{2}-A_{2}=0
\end{gathered}
$$

If all $\mathrm{P}_{i}, A_{i}>0$ in the optimal solution, then the first-order conditions indicate that $\lambda_{1}=\lambda_{2}$ and that $2 a_{1} A_{1}=2 a_{2} A_{2}=$ $2 d\left(P_{1}+P_{2}\right)$, (i.e., $\left.\mathrm{MAC}_{1}=\mathrm{MAC}_{2}=\mathrm{MDC}\right)$. In a watershed with $n$ sources of pollution, optimal abatement occurs where $\mathrm{MAC}_{1}=\mathrm{MAC}_{2}=\ldots=\mathrm{MAC}_{n}=\mathrm{MDC}$, where $\mathrm{MAC}_{i}$ is the marginal abatement cost or increased cost associated with a unit reduction in relevant emission for source $i$, and MDC is the marginal damage cost from all pollution at the point of measurement. If for the same amount of abatement $\left(A_{1}=A_{2}\right)$ we have $\operatorname{MAC}\left(A_{2}\right)>\operatorname{MAC}\left(A_{1}\right)$, then at the optimum $A_{2}<A_{1}$. That is, the most abatement should be accomplished by source 1 , the source with the lower marginal abatement cost.

This concept is illustrated in figure 1 , where $a_{1}=\$ 1, a_{2}=$ $\$ 1.5$, and $d=\$ 2$. The optimum level of pollution abatement occurs where the sum of total abatement plus damage costs is a minimum (fig. 1a). The optimal solution calls for the abatement of 154 tons, with source 1 removing 92 tons and source 2 removing 62 tons. This level of removal equates the marginal abatement costs for each source to each other and to the aggregate marginal damage cost curve at $\$ 185$ per ton (fig. 1b). Note that the solution requires equating marginal 


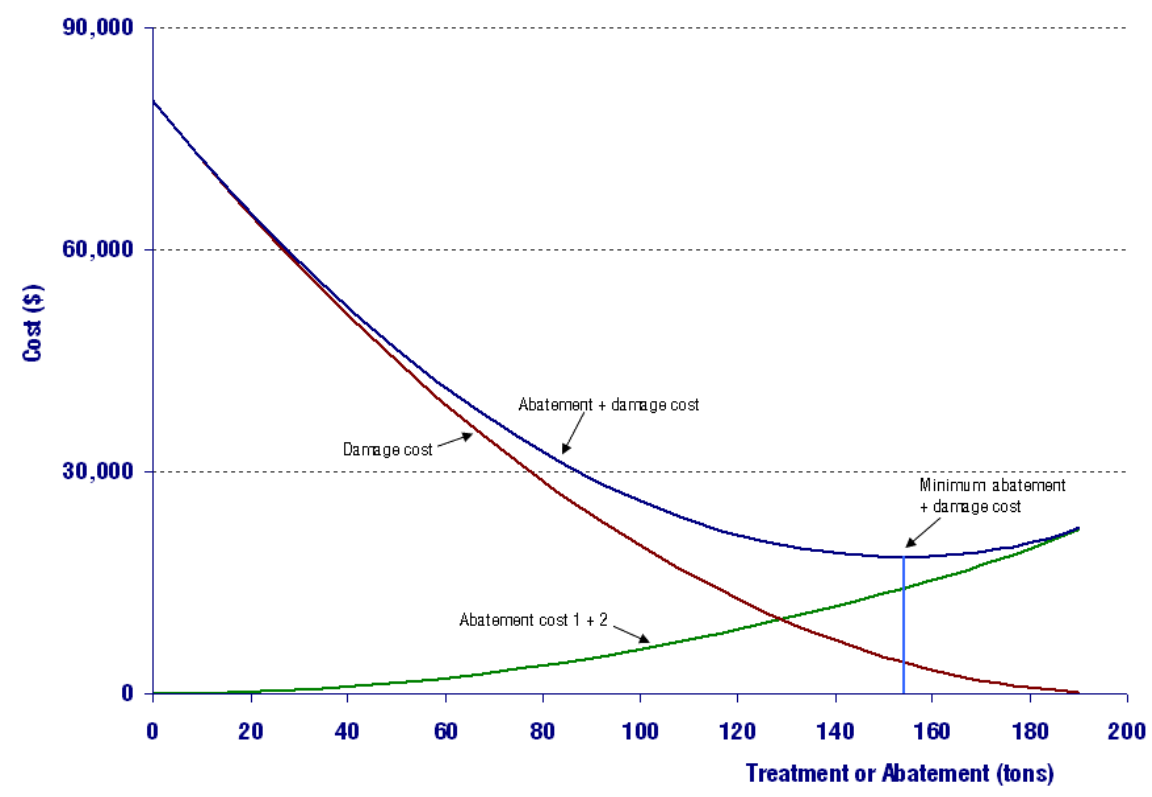

(a) Total damage and abatement costs

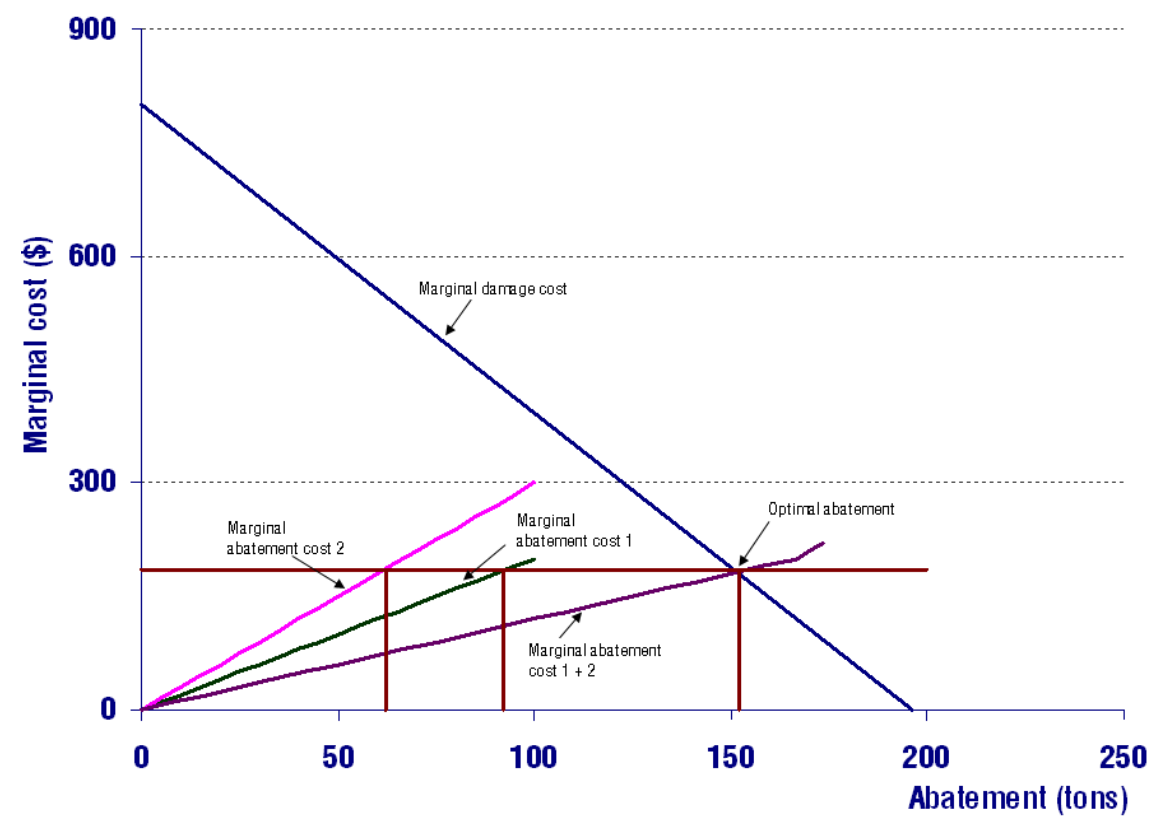

(b) Marginal damage and abatement costs

Figure 1. Total and marginal abatement and damage costs for the example problem. The total of damage plus abatement costs (a) is minimized where the sum of marginal abatement costs equals marginal damage cost (b).

abatement costs across sources and does not assume equal or proportional abatement across sources.

In contrast to the static approach outlined above, Conrad and Clark (1987, section 4.3) discuss the dynamic approach to determine the optimal abatement levels for a pollutant that accumulates over time. This approach can be illustrated with adjustments to the previous model. In the dynamic case, let $R_{t}$ be the carry-over of accumulated pollution from past periods. The amount of carry-over pollution that survives from one year to the next is $v R_{t}$, and $w P_{t}$ is the amount of current pollution that survives to time $t+1$. This can be stated as $R_{t+1}=v R_{t}+w P_{t}$. The dynamic TMDL standard that minimizes the discounted sum of abatement plus environ- mental damage costs can be determined from the solution to the following problem:

$$
\begin{aligned}
& \operatorname{Min} W(P)=\sum_{t=1}^{N}\left[a_{1}\left(E P_{1 t}-P_{1 t}\right)^{2}\right. \\
& +a_{2}\left(E P_{2 t}-P_{2 t}\right)^{2}+d\left(P_{1 t}+P_{2 t}+R_{t}\right)^{2} \\
& \left.+\lambda_{t}\left(R_{t}+w\left[P_{1 t}+P_{2 t}\right]-R_{t+1}\right)\right] \div(1+i)^{t}
\end{aligned}
$$

Since $A_{i t}=E P_{i t}-P_{i t}$, the amount of abatement by each source $\left(A_{i t}\right)$ in equation 1 is replaced by the term $E P_{i t}-P_{i t}$ to reduce the number of constraints. Total pollution that causes 


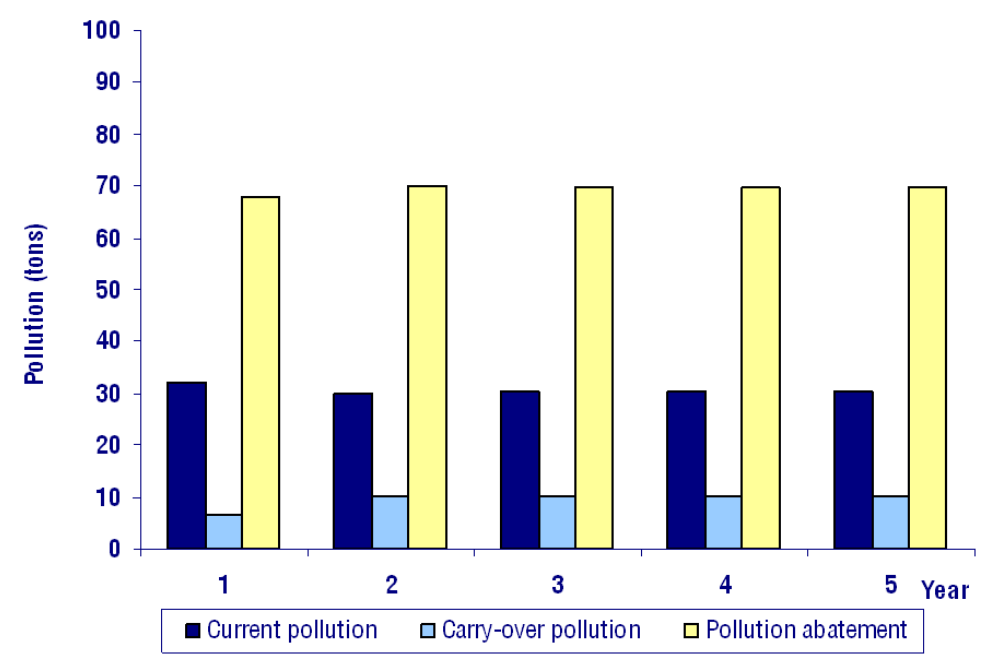

Figure 2. Dynamic adjustment to an optimal rate of abatement with a cumulative pollutant. Total pollution in each year equals pollution emitted by source 2 in that year plus carry-over pollution from previous years. Source 1 abates all of its pollution.

damage each year is equal to $R_{t}+P_{t}$. If the discount rate $(i)$ is $0.1, v=0.1$, and $w=0.3$, the model will reach an optimal steady state in about four years, as shown in figure 2 . The amount of current annual abatement in the dynamic case is increased to 169.8 tons from 154 tons in the static case, with source 1 abating 100 tons and source 2 abating 69.8 tons (fig. 2). In year 0 prior to pollution controls, each source emits 100 tons and there is 0 abatement. Carry-over pollution from year 0 totals 66.7 tons (equal to 0.3 times 200 tons of current pollution plus 0.1 times 67 tons pollution carry-over from the previous year). By year 4, a steady-state solution is reached in which new annual pollution from source 2 (fig. 2) is 30.2 tons. Carry-over pollution from previous years in the steady state is 10.1 tons (equal to 0.3 times 30.2 tons of new annual pollution plus 0.1 times 10.1 tons of carry-over from the previous period). The total annual pollution is 40.3 tons (30.2 tons annual pollution plus 10.1 tons of carry-over pollution) compared to 46 tons of annual pollution in the static case. Optimal abatement for source 2 would be higher than the steady-state amount in the first three years as carry-over pollution is reduced from the initial 67 tons to 10.1 tons. The marginal abatement cost increased from \$185 to \$209 per ton. The marginal abatement costs would be equal among sources had source 1 not reached its upper limit of 100 tons.

The relationship between the marginal cost of abating current pollution and the marginal cost of damage caused by current and residual pollution is explained by the first-order conditions with respect to current pollution from source 2 :

$$
\begin{aligned}
& \partial W / \partial P_{2 t}=-2^{*} a_{2}\left(E_{2 t}-P_{2 t}\right) \\
& +2 d\left(P_{1}+P_{2}+R_{t}\right)+\lambda_{t} w=0
\end{aligned}
$$

The coefficient $w$ represents the change in carry-over or cumulative pollution per unit of current pollution. The term $\lambda_{t}$ measures the increase in the cost of abatement due to an additional unit of carry-over pollution. Let MRAC be the product of $\lambda_{t}$ times $w$, which represents the increase in cost due to another unit of carry-over or cumulative pollution. For each source that is not at its upper bound (source 2 in this case), $\mathrm{MAC}_{2}=\mathrm{MDC}+\mathrm{MRAC}$. In the dynamic case, optimal current abatement costs will exceed MDC to compensate for the accumulation of carry-over pollution from current pollution. In the current example, the respective values for $\mathrm{MAC}_{2}, \mathrm{MDC}$, and MRAC are $\$ 209.40=\$ 161.10+\$ 48.30$.

Dynamic optimization of the TMDL standard would also be necessary if there were a systematic increase or decrease in total abatement costs or damage costs. Higher damage costs from increasing values over time placed on recreational uses, public water uses, or biodiversity would argue for lower TMDLs.

For this approach to be operational in a watershed, empirical estimation of both abatement and environmental damage costs for the selected pollutant or pollutants is needed. The above example applies to a pollutant that is not degraded from the source to the point of measurement. In the case of pollutants that are degraded, it would be necessary to consider the specific spatial allocation of the sources and the point(s) of measurement and include transfer coefficients that reflect the proportion of the quantity emitted from each source that reaches the receptor (for example, see Tietenberg, 2003, chapter 14).

The following principles can be drawn from the above example:

- The process of setting water quality standards for water bodies and developing TMDL plans that maximize net social benefits requires an economic valuation of both treatment and damage costs. Damage costs must include monetary costs and non-monetary costs, such as recreational, aesthetic, and biodiversity losses that occur both within and beyond the watershed.

- Setting the best water quality standard and associated TMDL and allocating the TMDL among sources are simultaneous problems. A two-step process, where first the water quality standard and associated TMDL are set and then an efficient allocation of the waste load is determined, can at best guarantee that the given TMDL is met at least cost. However, the two-step process does not imply that the benefits of meeting the TMDL will exceed or equal the costs of meeting the TMDL.

- An inefficient policy to implement the TMDL or allocate the waste load among sources (i.e., uniform allocation of waste load among sources) will increase the overall cost of abatement. This allocation means that 
marginal abatement costs will equal marginal damage costs with less abatement. An efficient method of waste load allocation among sources will make it more desirable to set a lower TMDL and have cleaner water than will be the case with an inefficient allocation.

\section{Synthesis of ECONOMIC MOdels FOR TMDL ASSESSMENT}

\section{Assessing Costs and Benefits of TMDL Plans}

Historically, the role of economic analysis in TMDLs has been confined largely to an assessment of alternative implementation options after the TMDL target has been set. However, as suggested earlier, in the broadest sense an efficient TMDL can be defined as a TMDL implementation that optimizes the TMDL target and achieves the given TMDL target at least cost. This definition of an efficient TMDL acknowledges a broader role for economic analysis than is usual in practice. It suggests that economic modeling and analysis can be employed in determining not only the TMDL allocation but also the overall target itself. This broader scope of economic modeling will entail the greatest benefit to society from TMDL implementation, but it also requires more sophisticated integration of economic and environmental water quality modeling systems.

As discussed earlier, the theoretically efficient allocation for a given TMDL target is achieved by assigning emissions to pollutant sources such that the MAC is equal among all sources. In practice, this exact equality may not be feasible. However, efficiency of TMDL implementation generally improves as one moves closer to the point of equal MAC among all sources. Economic models provide estimates of production costs at various levels of emissions. Abatement costs can be obtained readily from these estimates, as the difference in production cost associated with two different levels of pollutant emissions, all else being equal.

\section{Economic Models and Equity Considerations}

The efficient TMDL allocation will lead to the most beneficial use of society's resources. In the efficient TMDL, some point and/or nonpoint sources may be asked to reduce pollutant levels by a greater proportion because they can do so at a lower cost per unit of pollutant reduction. For example, experience with soil erosion showed that highly erodible lands (HEL) contributed more than their share of sediment (USDA-NRCS, 2005). Since HEL acres are often located on steep slopes with shallower, less productive soils, soils with lower income producing potential are often the main contributors to sediment loads. To the extent that such soils are located on lower income farms, a heavier proportion of the burden of reducing soil erosion falls on lower income farmers unless participation in sediment reduction programs is voluntary. However, society may have other goals in addition to efficiency, such as ensuring an equal distribution of costs among polluters or distributing costs according to polluters' abilities to pay. These goals raise questions for TMDL implementation regarding (1) how equity is to be defined and (2) the desired tradeoff between equity and efficiency (Spurlock and Clifton, 1982). Definitions might include: (1) equal pollution reduction, i.e., allocate the amount of pollution control proportionally among sources according to the amount of pollution generated; and (2) equal pollution costs, i.e., equalize the costs of pollution control among all sources in the watershed. Under definition 1, all sources might be asked to reduce their emissions by the same percentage, regardless of the cost of achieving this reduction. Under definition 2, each source might be asked to incur the same amount of cost regardless of the amount of pollution reduction obtained. Definition 2 could be modified to account for the economic size of the source. For example, a point source with ten times the annual value of sales compared to an economically small nonpoint source might be asked to spend ten times as much on pollution control as the nonpoint source.

Depending on the definition of equity, the equitable level of emissions may be related to the damage caused by each source owner's emissions and/or each source owner's costs of reducing emissions. Equitable allocation of pollution responsibility should also consider the economic forces that constrain the source owner to produce in the manner chosen. These economic forces may be due to other industries within the same watershed or planning region. For example, integrated firms may concentrate livestock or poultry production within a relatively small geographic region. Individual livestock or poultry farm contractors who produce the animals or birds according to specified contracts may be responsible for manure disposal but have little land on which to spread the volume of manure in an environmentally safe manner. In these circumstances, placing all the burden of environmentally safe manure disposal on farm contractors may be inequitable given the economic constraints under which they operate.

Together with water quality models, economic simulation models can be used to estimate the distribution of pollutant loads among individual point and nonpoint sources that maximizes stakeholder goals based on both equity and efficiency. Water quality models can provide information on how much impairment to public resources is caused by each source owner's emissions. Economic simulation models can provide information on how much cost is incurred by each point and nonpoint source owner in reducing emissions. The overall costs in the watershed and distribution of costs among pollution sources can be compared using different rules for allocation of pollution reductions among sources (Miller and Gill, 1976; Spurlock and Clifton, 1982). Multiple goal programming techniques can be used to optimize a weighted combination of goals that include efficiency (minimize overall costs to the watershed of achieving a specified pollution reduction) and equity (distribute costs equally among sources, based on the definition of equity) (McCarl and Spreen, 1997).

\section{Benefit Valuation and TMDL Assessment}

In some cases, quantitatively valuing environmental improvements is straightforward. For example, benefits from reduced public water treatment costs, reduced dredging costs, or increased reservoir life can be estimated by economic engineering methods. Often, however, placing quantitative values on environmental goods such as those with recreational and aesthetic uses can be challenging because markets for these goods do not exist, making it difficult to measure their benefits. Over the past two decades, several valuation methods have been developed, some using statistical survey techniques, to infer the values that consumers place on environmental goods and services (Mitchell and 
Carson, 1989). Two main categories of valuation methods are employed by economists to estimate the value of environmental goods and services: revealed preference methods and stated preference methods (Smith, 1993; Adamowicz et al., 1994). These valuation methods play a crucial role in cost-effective TMDL implementation because policymakers need information on the value of the resource they are trying to protect. In the absence of resource valuation methods, public officials may spend large amounts of resources to protect an environmental good that is actually valued very little by the public, while another, higher valued resource receives little or no attention. While it has not been typical practice in TMDL planning, the effectiveness of TMDLs can be increased by including information from economic valuation models.

With revealed preference models, economists use statistical methods to infer the value of a nonmarket good based on actual choices of consumers. In other words, valuation is based on preferences that have been revealed by actual consumer decisions such as trips to a lake, park, or other public resource. Travel cost models (TCMs) are among the most widely used revealed preference models. The rationale behind the use of TCMs is that the environmental resource at a given site is at least as valuable as how much it costs to travel to that site (Shaw, 2005).

Stated preference models, on the other hand, use surveys to elicit consumer valuation of environmental resources contingent on hypothetical situations (Mackenzie, 1993; Boxall et al., 1996). Conjoint analysis and contingent valuation methods are two prominent types of stated preference models used by economists. In contingent valuation, consumers are presented with a hypothetical scenario in which they are often asked how much they are willing to pay to conserve or improve access to an environmental resource or enhance its quality. Conjoint analysis models, also known as choice experiments, present consumers with a series of hypothetical choices representing alternative environmental resources and ask them to choose their preference, rank the alternatives, or rate them. With conjoint analysis, multiple criteria or attributes are often specified explicitly for each environmental resource alternative. Thus, the survey responses can be used to derive estimates of the values of the individual attributes of the environmental resource, essentially a nonmarket equivalent of hedonic pricing methods. Conjoint and contingent valuation methods are both based on the stated preferences of consumers rather than preferences that are actually revealed through behavioral choices.

While both revealed and stated preference methods have advantages and limitations, stated preference methods are the only viable options in certain environmental valuation situations. A classic case of environmental valuation efforts in recent history relates to the contingent valuation studies that were conducted in the aftermath of the 1989 Exxon Valdez oil spill off the Alaskan coast (Arrow et al., 1993; Smith, 1993). Concise and nontechnical discussions of environmental valuation methods are given by Loomis (2005), Shaw (2005), and Stevens (2005).

\section{Uncertain Benefits and Costs}

The damage and abatement costs presented in figure 1 are based on the assumption that damage and abatement costs are known with certainty. Estimates of pollution damage and abatement costs are subject to three types of risk or uncertainty: (1) economic uncertainty, (2) environmental uncertainty, and (3) model uncertainty. Economic uncertainty due to variations in prices, costs, yields, and policies influences farmers' crop and livestock production choices, which influence pollution potential. Farmers may be risk averse, meaning they are willing to pay to reduce risk to an acceptable level (Robison and Barry, 1987). Farmers' risk aversion makes it difficult to estimate responses by farmers and other stakeholders to pollution-reduction policies and the costs of such responses (Bosch and Pease, 2000). TMDL policies that increase the uncertainty faced by farmers may increase their costs of managing risks as well.

Environmental uncertainty stems largely from weather variability, which influences the potential for leaching and runoff from crop and livestock production activities. Model uncertainty is due to lack of knowledge about pollution processes and uncertainty about parameter values (Shirmohammadi et al., 2006). Policymakers must base estimates of damages and costs on limited monitoring data collected under variable streamflow and weather conditions. Wide confidence intervals may surround the true damage resulting from pollution because of limited monitoring data (National Research Council, 2001). This uncertainty makes the estimated benefits of pollution reduction uncertain as well. Risk-averse downstream stakeholders will be concerned about the variability of pollution loads and/or concentrations and may be willing to pay a premium to reduce variations in water quality and pollution loads.

\section{Economic Models Avallable for TMDL Assessment}

Economists have developed a variety of models for environmental policy assessment, and some of these are very suitable for TMDLs. While most economic models are not as widely used as the major water quality models, they are still recognized within the profession and play an increasingly greater role in TMDLs as economic analysis is afforded a more central place in TMDL implementation. Most economic models are developed and used by a small team of researchers for specific projects because the model design and requirements are site specific. However, a few economic models have enjoyed more widespread use. The following synthesis illustrates the kinds of models that are available but is not intended to serve as a comprehensive listing of the economic models available for analysis of TMDLs.

Two main kinds of economic models can be distinguished based on design: simulation models and optimization models. Simulation models are models that directly represent the observed activities and behavioral patterns typical of the farms or economic agents being modeled with no normative consideration of what is the "best" behavioral response in any given situation. Such models mimic the observed economic choices that the farms or modeled units portray in the real-world setting. The strength of simulation models is in showing how decision makers respond in various situations and the resulting implications for economic returns and pollution runoff. Simulation models include FLIPSIM: Farm Level Income and Policy Simulation Model (Richardson and Nixon, 1981; Richardson et al., 1993; AFPC, 2005), FEM: Farm-level Economic Model (Osei et al., 2000a, 2000b, 2000c; Gassman et al., 2002), and ADAPT: Agricultural Drainage and Pesticide Transport (Westra et al., 2004). 
Optimization models assume that the farmer, landowner, public agent, or other decision maker seeks to maximize profits, utility, public welfare, or some other objective subject to various constraints. Using these assumptions, optimization models provide an outline of choices or levels of decision variables (such as how much area to plant in corn, how much fertilizer to use, or where to apply manure and how much per acre) that result in the optimal ("best") solution. Static optimization models provide the optimal solution but do not necessarily show how the solution is reached. However, optimizations can provide additional information. For instance, optimization models can yield a set of shadow prices or Lagrangian multipliers that can be used to set pollution taxes for each land use and associated soil type in the watershed if such taxes are politically feasible. Optimization models have also been used to explore the effects of the spatial resolution of farm models on predicted costs and runoff reductions of pollution control practices (Bonham et al., 2006). Optimization models used in economic analysis of TMDLs and/or other environmental practices and policies include those of Govindasamy et al. (1994), Giasson et al. (2002), and Feinerman et al. (2004).

Water quality simulation models can provide data for both economic optimization and simulation models including estimates of crop outputs and runoff of sediment, nutrients, or pesticides under various cropping practices for a watershed composed of numerous soil types. Models such as SWAT (Soil Water Assessment Tool) are being used by researchers in several states (Bosch et al., 2004). These models subdivide watersheds into hydrologic response units (HRUs) that have a common land cover and soil type.

A useful synergy exists between economic simulation and optimization models. Just like their water quality counterparts, economic simulation models can be made very complex. In fact, some economic simulation models are highly nonlinear, multistage process models. By contrast, in order to ensure an optimal solution, most optimization models are relatively simple and mostly linear. For TMDL analysis, the output from a series of simulations in which management practices are simulated on individual HRUs can be incorporated into a programming model. The programming model can then be solved to determine the best management practice for each HRU so that the TMDL can be met at least cost. The solution to a properly formed programming model satisfies the requirements for cost minimization that MACs are equated across individual HRUs.

Environmental uncertainty can also be incorporated in optimization models. Teague et al. (1995) and Qiu et al. (1998) have shown that Target MOTAD (Minimization of Total Absolute Deviations) forms of optimization models can be used to analyze weather-related probabilities of meeting discharge levels. Target MOTAD is a method of risk programming that maximizes an objective function (such as expected net returns) subject to constraints on deviations below or above a desired target (such as pollution levels). More recently, Qiu et al. (2001) have shown that safety-first programming models allow the decision maker to specify the desired compliance probability of not exceeding the target level of pollution. Safety-first risk programming maximizes an objective function (such as expected net returns) subject to a probabilistic constraint on deviations above a desired target (such as pollution).
Some water quality models include an economic component. A good example is the EPIC (Environmental Policy Impact Climate) model (Williams, 1990), which is the forerunner of another environmental water quality model, the APEX (Agricultural Policy/Environmental eXtender) model (Williams, 1995; Williams and Izaurralde, 2006). Both of these models are field-scale environmental simulation models that are widely used for work related to TMDLs. The economic components of these models consist of cost coefficients that are multiplied by specific model units, such as field sizes or herd sizes, to obtain total costs or economic impacts. These estimates are provided by the models to give an initial indication of the relative magnitudes of the costs of some practices. However, virtually all of these cost estimates have to be obtained outside of these models. The cost estimates are inadequate for more comprehensive economic assessments because they do not account for opportunity costs of meeting environmental restrictions. Opportunity costs are incurred by farms when they have to limit profitable enterprises or change production practices in order to comply with environmental restrictions. For example, farms may have to limit numbers of livestock produced or haul manure off the farm due to limits on manure spreading.

\section{INTEGRATED ECONOMIC AND WATER QUALITY (BiophysicAl) MODEls}

Integrated economic and water quality modeling began with the analysis of options for controlling soil erosion. Sediment and nutrients are the two most pervasive pollutants in the U.S. (USEPA/USDA, 1990). Soil erosion analysis was facilitated with the Universal Soil Loss Equation, which provided site-specific estimates of soil erosion without the need to model individual storm events. Modeling nutrient pollution from rural watersheds was far more challenging than modeling soil erosion due to the considerable cost of modeling individual storm events. The major breakthrough in integrated modeling of watersheds occurred fairly recently. With the advent of very fast computers, scientists began to model 30 years of storm events, matching cost-effective remedies, such as grassed waterways, to individual farm and field sites and then using the field runoff data as input to a watershed model to address nutrient problems in watersheds (Osei et al., 2000a).

The majority of economic models used with water quality models for TMDL development and implementation are optimization models. Figure 3 portrays the traditional role of optimization models in TMDL development and implementation and other environmental policy assessment in general. When optimization models are used in concert with water quality models, the goal is usually to determine the optimal or cost-effective solution to an environmental problem, given a variety of policy or practice options. Policy options could include alternative TMDL allocations among sources.

Practice options could include various BMPs or other technologies. Water quality models could estimate the impacts of these alternatives on water quality indicators of interest to stakeholders. Costs or other economic indicators associated with these alternatives are also obtained from various sources, perhaps from economic simulation models. The key role of the economic optimization model is to determine the optimal combination of alternative policies and/or practices for the planning region or watershed. For a 


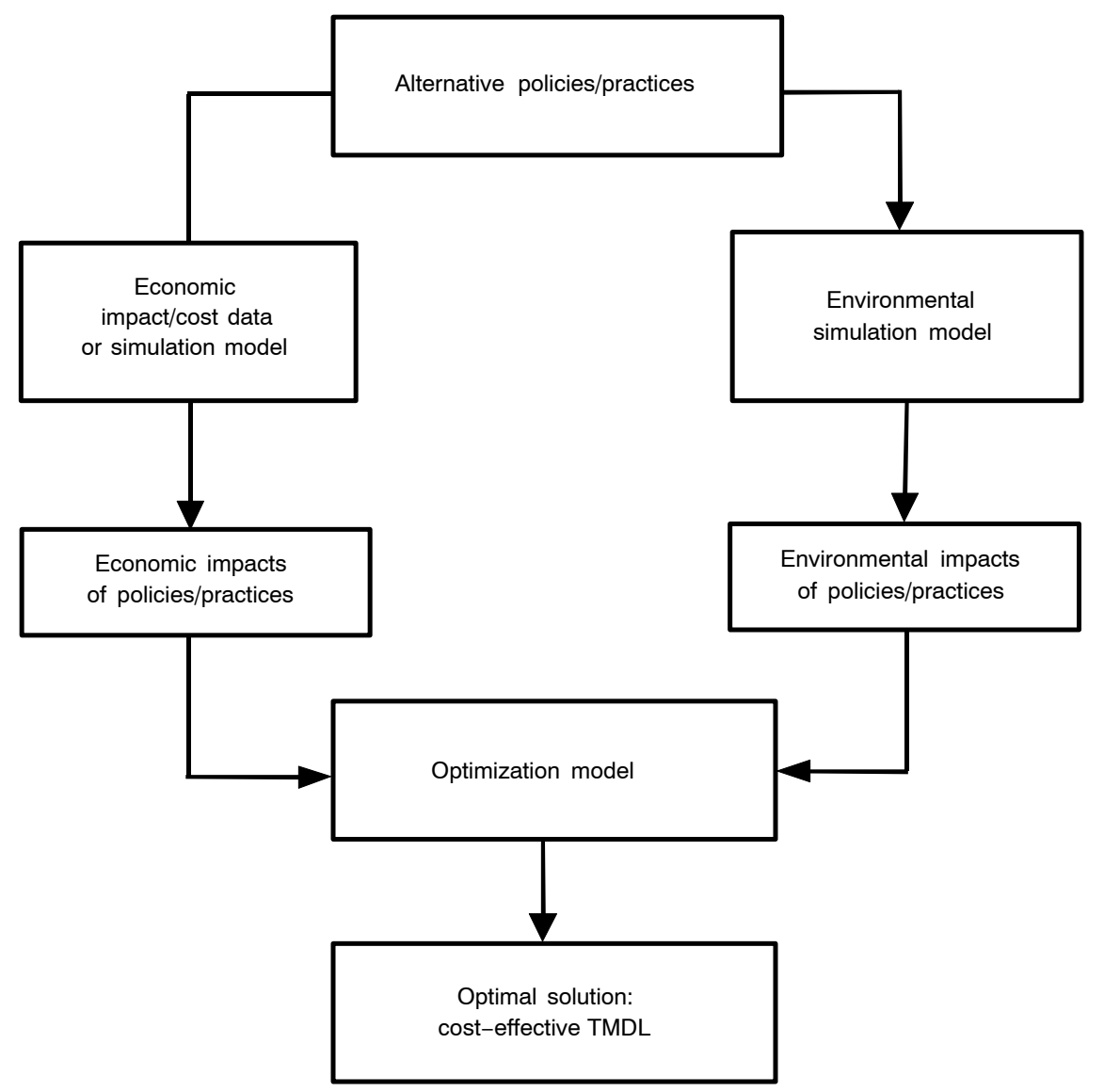

Figure 3. Economic optimization model integrated with environmental water quality model.

watershed TMDL, the optimal combination could mean the "best" allocation of load reductions among source owners, as well as the most cost-effective technology each source owner could use to meet the prescribed load reduction. Optimization may be performed at both farm and watershed levels. Carpentier et al. (1998) generated individual farm cost functions for nitrogen runoff reduction by maximizing farm net revenues subject to varying constraints on nitrogen runoff. These farm cost functions were entered into a watershed model to minimize overall costs of reducing nitrogen runoff by allocating reductions among farms. Veith et al. (2003) used a genetic algorithm to optimize pollution reduction from the placement of agricultural BMPs within a watershed. Another example of integrated modeling systems employing economic optimization models is CEEPES: Comprehensive Environmental Economic Policy Evaluation System (Bouzaher and Manale, 1993).

Economic simulation models are also integrated with environmental water quality models. The linkage between the models can be dynamic, affording opportunity for more accurate determination of the costs and environmental

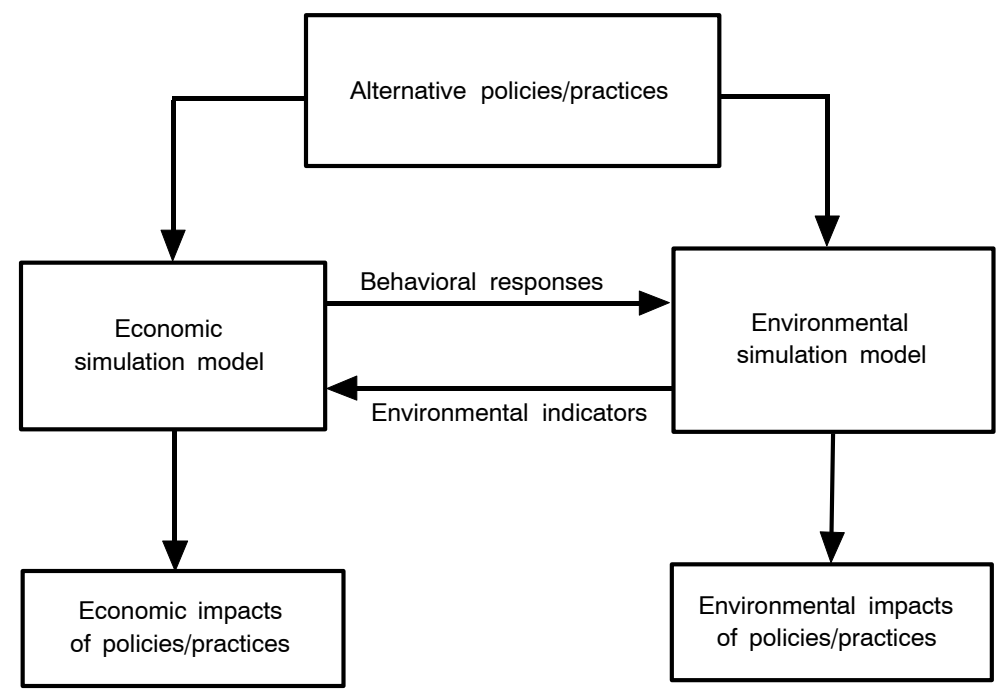

Figure 4. Schematic of integrated economic and environmental water quality simulation models. 
impacts of alternative policies or practices. Figure 4 illustrates the linkages between economic and environmental water quality simulation models.

Unlike the case with optimization models, the linkage between economic simulation models and water quality models readily allows for dynamic feedback loops. Behavioral responses to policy or practice changes can be determined in the economic models and passed on to water quality models for more accurate assessment of the environmental impacts. Similarly, economic simulation models can receive data on environmental indicators and simulate new behavioral responses, which in turn can be passed on to the water quality models. Model linkages can be updated at multiple time periods in order to provide estimates of cumulative environmental and economic impacts over time. The economic and environmental impacts generated from such linked models do not necessarily select an optimal solution, but nonetheless the models provide more accurate estimates of the impacts of proposed changes over time compared to static models.

The CEEOT (Comprehensive Economic and Environmental Optimization Tool) modeling system (Gassman et al., 2002) is an example of an integrated modeling system that includes linked economic and environmental simulation models. The CEEOT system supports modeling of individual farms or representative farms using the economic simulation model FEM. The environmental models include APEX (Williams, 1995), which is a modified version of the EPIC model (Saleh et al., 2000; Williams, 1990), and the Soil Water Assessment Tool (SWAT) watershed model (Arnold et al., 1998). APEX calculates edge-of-field runoff of nutrients, providing field runoff data as input to SWAT. The SWAT model identifies stream water quality impacts that would result from a variety of options for managing farmers' fields, including reducing nutrient applications, applying erosion control practices, installing grassed waterways and buffers, and other options (Keith et al., 2000). The combination of APEX, SWAT, and FEM can be used to estimate costs and effectiveness of each option as well (Osei et al., 2000a, 2000b, 2000c; Gassman et al., 2002; Keith et al., 2000). FEM has been used in conjunction with APEX to evaluate BMPs for a number of diverse watersheds, including a watershed in northeast Texas with intensive pasture-based dairy production (Osei et al., 2003; McNitt et al., 1999) and a watershed in central Texas with intensive dry-lot-based dairy production (upper North Bosque river) (Pratt et al., 1997; Osei et al., 2000c).

Wu and Babcock (1999) developed procedures to use the hundreds of thousands of field sample points available through the National Resource Inventory (NRI) to provide site-specific analyses for thousands of watersheds for what it used to cost to model just one watershed. Models are run at individual field sites consistent with these models' intended use, and they are calibrated to field experimental data. Pollutant runoff estimates for 30 years of storm events for 120,000 individual field sites are aggregated to the county level or to the watershed level. Integration of economic and water quality models in these applications enabled the researchers to provide information on the costs and environmental impacts of a wide array of practices at much lower cost than previous analyses. Model results can help states set priorities for TMDL programs, identify cost-effective practices, and track progress toward improving water quality, as improved practices are implemented. $\mathrm{Wu}$ and Babcock (1999) found that new technologies for measuring (or crediting) farm-produced nutrients could reduce nitrate runoff in most Midwestern counties (or, presumably, in most Midwestern watersheds) by $15 \%$ to $30 \%$ at essentially no cost to the farmer.

These advances have greatly reduced the cost of water quality and economic modeling of watersheds for TMDL development. With 20,000 impaired watersheds in the U.S. and the courts calling for rapid implementation of TMDL programs, the modeling advances are an important step in effective planning and implementation of TMDL programs.

\section{OVERCOMING BARRIERS TO IMPLementing TMDL Policies}

The TMDL planning and implementation process gives watershed managers and stakeholders flexibility in addressing pollution from agriculture and other nonpoint sources because loading-reduction goals and practices for achieving them are based on site-specific conditions. This process contrasts with the more rigid technology standards that have been applied in the past to point sources, which are now being superceded by more flexible performance-based discharge limits in most cases. For example, although National Pollution Discharge Elimination Standards are designed with great care to avoid unnecessary costs and to allow some flexibility, they still must address all livestock operations of a certain size. An outcome of the TMDL process in a watershed might be instead to achieve a water quality goal for that watershed by focusing on improved fertilizer management or stream buffers, without placing the relatively more costly requirements on livestock sources of pollution within the watershed. This flexibility allows local policy makers to target resources and to set priorities between watersheds and between pollution sources within each watershed, as well as to set specific goals and track progress in reducing pollution. Because of this flexibility, economic analysis of benefits and costs can play a large role in designing TMDL programs.

Yet the same flexibility in designing site-specific, performance-based programs has created immense technical barriers that have slowed the development of TMDL programs. States have listed over 20,000 watersheds as impaired, and until recently, it was very challenging and costly to model even one watershed (National Research Council, 2001) in a manner that would support the targeting, identification of goals, priority setting, and tracking of progress that are critical to the success of a TMDL program. Since TMDL programs are performance driven, it also is necessary to set credible goals and track progress in reaching the goals in order to attain the participation of farmers and other stakeholders. As a result of all these technical barriers to implementing TMDL programs, the burden of reducing pollution has fallen in the past very largely on industrial and urban sources (Boyd, 2000), even though far more cost-effective remedies are available to agriculture in many cases.

\section{Comparing Benefits AND Costs}

As noted above, economic analysis is relevant to decisions regarding the setting of water quality standards based on water body use designations, which are quantified in a TMDL, as well as determining load allocations and selecting 
practices for achieving them. Point sources of pollution have been the past focus of water quality programs, and a relatively larger portion of point-source pollution has been controlled compared to nonpoint-source pollution. Therefore, the focus of economic model analyses has been on addressing the benefits and costs of setting TMDL standards and implementing practices to achieve the standards in rural watersheds where nonpoint-source pollution predominates. However, economic and environmental models can be adapted to consider costs and benefits of reductions from both point and nonpoint sources.

In contrast to the site-specific analysis regarding the cost-effectiveness of practices on field sites, analysis of the economic benefits of reducing pollution from rural watersheds typically offers results for whole regions rather than for individual watersheds. Regional water quality benefits from reducing soil erosion have been estimated for municipal water treatment facilities, marine and freshwater fisheries, navigation, flooding, industrial production, reservoirs, and water-based recreation (USDA-ERS, 2004; Ribaudo, 1989). Research findings from these studies suggest that water quality benefits from reducing sediment losses are often modest in the most intensively farmed areas. Comparing the information regarding benefits and cost suggests that many TMDL programs dealing with sediment and nutrient pollution should set feasible goals, as well as: (1) target highly erodible land (USDA-NRCS, 2005); (2) focus TMDL remedies on the more cost-effective practices such as fertilizer and manure management (Fuglie and Bosch, 1995; Musser et al., 1995; Ogg, 1999; Wu and Babcock, 1999), buffers, and related practices; and (3) consider multi-media benefits, including wildlife benefits, benefits in reducing greenhouse gases, and other benefits rather than just the water quality benefits of practices. For example, the USDA Economic Research Service (USDA-ERS, 2004) found that shifting land from crop uses to native grass covers by enrolling it in the Conservation Reserve Program (CRP) produced wildlife viewing benefits that exceeded the water quality benefits.

Yet even in heavily farmed Midwestern regions, studies of individual lakes suggest that there are opportunities to achieve much greater than average benefits, suggesting different, and more ambitious, water quality protection strategies may be warranted in some cases. In these cases, higher use designations for the water bodies may be justified, which would lead to more stringent TMDL standards. For example, benefit analyses focusing on individual Iowa lakes have found that very large water quality benefits occur, but only in watersheds where pollution remedies can achieve water clarity (Egan et al., 2004). These larger benefits stem from the many recreational visits that Iowans make to their lakes and from the heavy value they place on clear water.

The Iowa findings also emphasize more generally the importance of thresholds in designating uses for waters, which lead to TMDL standards for watersheds. For example, in watersheds that are heavily forested, it is presumably easier to reach the water quality thresholds and attain water clarity than in watersheds that are more intensively farmed.

Where water clarity is not a feasible goal, TMDLs may choose to focus, instead, on implementing relatively lowcost remedies, such as fertilizer management, reduced tillage/residue management, stream buffers, or grassed waterways. Where large benefits are attainable through higher use designations for water bodies, it may be practical to set relatively ambitious nutrient and sediment reduction goals aimed at attaining the thresholds necessary for restoring water clarity. More costly practices, such as shipping manure out of the watershed (Ogg, 1999), could be reserved for watersheds where the highest quality of water (clear water) can be achieved or where special demands are placed on the water, such as the demands placed on reservoir water used to supply drinking water to cities or the demands placed on large estuaries used heavily for fishing and recreation.

\section{ATtAINING ECONOMIC EFFicienCy FROM TMDL Programs}

The U.S. Congress (1972) designed TMDL programs to deal with the pollution that remains after point sources of pollution were addressed. This delayed approach had the merit of providing time to overcome the many technical barriers that confronted TMDL programs in the past (Boyd, 2000). Although the past gains in reducing pollution from industry came at a considerable cost, past gains in greatly reducing soil erosion and in reducing fertilizer use per bushel of corn emphasize, again, the opportunities for agriculture to contribute environmental gains without imposing substantial costs or to employ strategies that balance costs with multi-media benefits.

Today, TMDLs have the flexibility and potentially the targeting mechanisms to design very low-cost strategies for reducing water pollution while also realizing multi-media benefits, including wildlife benefits. The potential economic efficiency gains from targeting national and local soil conservation efforts became evident nearly 25 years ago, when National Resource Inventories (NRI) data sets were used to document that nearly two-thirds of the soil erosion in excess of sustainable rates (about 5 tons per acre) originated from a tiny portion (3.5\%) of U.S. cropland (Ogg et al., 1982). The approach of Wu and Babcock (1999) facilitates the analysis of targeting strategies at a regional or statewide scale. Using a similar approach, Feng et al. (2004) have developed more sophisticated targeting strategies to sequester carbon and reduce sediment-related nutrients for the Upper Mississippi watersheds. We now have an opportunity to use the models and research findings from economic analyses, such as those described above, to achieve environmental benefits from TMDLs in a much more cost-effective and balanced manner than in the past. Ideally, these regional or state models, with site-specific detail, can be used to identify opportunities and priorities that could then be used to develop statewide strategies supporting TMDL development.

One barrier to targeting might be watershed stakeholders' concern that the distribution of costs for pollution control be equitable. This concern might be addressed with pollution trading programs, whereby polluting sources receive and are allowed to trade pollution allowances. For pollution trading programs to work, there must be an incentive to trade, such as a regulation prohibiting sources from emitting pollution in excess of an allocated allowance. While most discussion of pollution trading programs have centered on trades between controlled point sources and uncontrolled nonpoint sources (Crutchfield et al., 1994; Chesapeake Bay Program, 2001), trades among nonpoint sources could be considered as well.

Multi-media impacts of practices to implement TMDLs should be considered. Practices that reduce pollution in one 
media may increase pollution in another. For example, reducing nitrogen volatilization from manure may improve air quality but also increase potential runoff and leaching from manure applied to crops. Alternatively, some practices may produce benefits in more than one media. For example, practices that reduce soil erosion may also improve stream habitat by reducing peak flows and increasing base flows.

\section{Documenting Past Gains}

A final, important step in designing TMDLs includes documenting gains over the past 25 years in reducing pollution loads. Nationally, soil erosion in the U.S. has been reduced by about $40 \%$, largely due to adoption of reduced tillage practices, as well as enrollment of land in the CRP (USDA, various years). In addition, ammonia fertilizer use per acre of U.S. corn has changed little over this period, while corn yields are up over $40 \%$ (Huang, 2005), suggesting a considerable increase in fertilizer use efficiency. These gains need to be disaggregated to the watershed level, and the associated water quality improvements need to be modeled and estimated as part of developing TMDL programs.

\section{Data Constraints and Model UnCertainties}

The role of economic models in TMDL development and implementation has been limited in the past (Portney, 1998) due primarily to a lack of appreciation of the role of economic and other social/behavioral forces in the success of environmental policies in general. However, perhaps a greater constraint to the use of economic models is the lack of data for reliable estimation of economic impacts and the modeling costs associated with the large number of impaired watersheds $(20,000)$ that need to be analyzed. The following are some of the key data needs that appear to be limiting the role of economic models in TMDLs in particular and in agricultural and environmental policy assessment in general (Osei, 2002):

- Fate and transport of manure nutrients and other agricultural waste. The recent ASABE revision of manure production characteristics (ASABE Standards, 2005) based manure nutrient fate and transport on prediction equations, which is a significant aid to obtaining more reliable nutrient loss and related cost information. Still, additional data on the production and fate of manure nutrients within various handling systems would be useful in developing baseline information and predicting pollution reductions from improved management systems.

- Farmer behavioral practices and perceptions. Farmer behavior, including crop and livestock management decisions, is the subject of regular USDA surveys and is accessible to researchers. Additional information on farmers' perceptions of the risks and costs of conservation practices and how such practices are implemented and maintained would help researchers more accurately estimate the costs and effectiveness of conservation practices.

- Characteristics of agricultural equipment and field operations. Numerous Cooperative Extension websites and publications provide information on ownership, repair, and maintenance costs of farm machinery based on ASABE formulas (FARMDOC, 2005). Further information on actual farm machinery ownership and operation patterns would increase the accuracy of estimated farm costs and incentives to meet conservation requirements.

While researchers have addressed the impacts of weatherrelated uncertainty on economic and environmental outcomes, there may be uncertainty about the accuracy of models due to incomplete knowledge about interactions of pollution with soil, water, and aquatic ecosystems. In a companion article in this TMDL collection, Shirmohammadi et al. (2006) address physical model uncertainty in greater detail. Monitoring results may also be uncertain due to limited monitoring data and the high costs of collecting data. As a result, there may be large uncertainties about damages from water pollution and the benefits of reducing pollution. The National Research Council (2001) recommends adaptive implementation of TMDLs while better data are being obtained. Adaptive implementation includes periodic assessment of watershed plans to determine if they are achieving designated uses for the affected water body. Plans not achieving their goals can be adapted based on scientific information (National Research Council, 2001). Another recommendation is to use statistical approaches to define waters, design monitoring procedures, and assess damages. Statistical approaches can ensure that maximum information on pollution damages and benefits of pollution reduction are obtained from limited monitoring resources. Both a preliminary list and an action list can be used instead of one 303d list to allow more time to gather data on the actual conditions of water bodies and the benefits of pollution reductions (National Research Council, 2001).

\section{Conclusions And Recommendations}

The TMDL process is based on states setting water quality standards for water bodies tied to designated uses that reflect the costs and benefits of the uses (Keplinger, 2003; National Research Council, 2001). Water bodies that are impaired by one or more pollutants and for which TMDL plan elements are required are then listed. The TMDL Water Quality Management plan for individual watersheds includes a listing of pollutant sources, an estimate of the reduction in pollution load that is required to achieve the designated use for the water body, an allocation of load reductions to different sources, and a plan identifying practices for implementing the load reductions. Setting goals for water quality improvement and devising plans to achieve these goals within the TMDL process can have important implications for public welfare. Setting a TMDL (pollution standard) that maximizes net social benefits requires an economic valuation of both treatment and damage costs. The total pollution allocation and its distribution among pollution sources should be determined simultaneously in order to maximize social welfare. A TMDL policy that is inefficient in terms of its design or implementation will increase the overall cost of abatement. However, the assessment of TMDL costs and the implementation of efficient TMDL policies are complicated by uncertainty about pollution damages and responses by stakeholders to pollution control policies. Economic simulation and optimization models are used to assess TMDL plans. Optimization models can estimate cost minimizing strategies to achieve TMDL goals, while simulation models have more flexibility to mimic the behavior of stakeholders in response to TMDL plans. 
Integration of economic optimization or simulation models with water quality models allows environmental impacts and costs of behavioral changes to be readily assessed. The accuracy of economic and environmental assessment can be increased by including dynamic linkages so that output from the environmental submodel is used as input to the economic submodel and vice versa.

If the goal of setting designated uses for water bodies and developing TMDL plans is maximization of social welfare, then the planning and implementation of TMDL plans require careful assessment of the benefits as well as the costs of cleaner water. Economic models can assist in this process. Higher water quality thresholds may be reserved for watersheds with higher estimated benefits from attainment of higher water quality and where that attainment is economically feasible and practical. However, even if the TMDL goal is a more restrictive one of achieving given water quality designations at minimum cost, economic models can play a large role in developing and implementing cost-minimizing plans. Costs of achieving standards can be reduced by targeting reductions at pollution sources with the lowest costs of achieving reductions. Trading programs can help achieve efficient targeting of pollution reductions while distributing pollution control costs equitably. There may be large uncertainties about both the benefits and costs of pollution reduction because of limited monitoring data, incomplete knowledge of how pollution affects aquatic ecosystems, and incomplete understanding of how stakeholders will respond to pollution control programs.

Several recommendations are suggested to increase the effectiveness of economic models for assisting in TMDL planning and implementation programs:

- Use economic models for analyzing costs and benefits of water quality improvements to assist in setting designated uses for water bodies and associated TMDL standards as well as in developing programs to implement the standards.

- Improve the ability of economic and environmental models to estimate pollution damages and benefits of pollution reduction by collecting better monitoring data on pollution levels and associated environmental damages.

- Improve the ability of economic models to estimate stakeholder costs of implementing TMDL programs by collecting more data on stakeholder responses to water quality improvement programs including TMDL programs.

- Extend economic and environmental models to consider multi-media impacts of pollution to more accurately estimate the costs and benefits of pollution reduction.

- Use economic and environmental models to assist in pollution targeting and trading programs to minimize the costs of achieving water quality goals, while distributing costs equitably among stakeholders.

\section{ACKNOWLEDGEMENTS}

This article is the one of a series of articles developed by members of the USDA-CSREES Regional Project S-1004 "Development and Evaluation of TMDL Planning and Assessment Tools and Processes" and the ASABE SW-21 Hydrology Committee. The authors would like to acknowledge the editorial leadership and coordination provided by
Rafael Muñoz-Carpena, Adel Shirmohammadi, and George Vellidis in this group effort. The authors also express appreciation to Karen Mundy for editorial assistance.

\section{REFERENCES}

Adamowicz, W., J. Louviere, and M. Williams. 1994. Combining revealed and stated preference methods for valuing environmental amenities. J. Environ. Econ. and Mgmt. 26(3): 271-292.

AFPC. 2005. Description of FLIPSIM: The farm-level income and policy simulation model. College Station, Texas: Texas A\&M University, The Agriculture and Food Policy Center. Available at: www.afpc.tamu.edu/models/flipsim/. Accessed 1 September 2005.

Arnold, J. G., R. Srinivasan, R. S. Muttiah, and J. R. Williams. 1998. Large-area hydrologic modeling and assessment: Part I. Model development. J. American Water Res. Assoc. 34(1): 73-89.

Arrow, K., R. Solow, P. R. Portney, E. E. Leamer, R. Radner, and H. Shuman. 1993. Report of the NOAA panel on contingent valuation. Federal Register 58: 4601-4614.

ASABE Standards. 2005. D384.2: Manure production and characteristics. St. Joseph, Mich.: ASAE.

Bonham, J. G., D. J. Bosch, and J. W. Pease. 2006. Cost effectiveness of nutrient management and buffers: Comparisons of two spatial scenarios. J. Agric. and Applied Econ. 38(1): 17-32.

Bosch, D. D., J. M. Sheridan, H. L. Batten, and J. G. Arnold. 2004. Evaluation of the SWAT model on a coastal plain agricultural watershed. Trans. ASAE 47(5): 1493-1506.

Bosch, D. J., and J. W. Pease. 2000. Economic risk and water quality protection in agriculture. Review of Agric. Econ. 22(2): 438-463.

Bouzaher, A., and A. Manale. 1993. Agricultural atrazine use and water quality: A CEEPES analysis of policy options. Staff Report 93-SR 66. Ames, Iowa: Iowa State University, Center for Agricultural and Rural Development.

Boxall, P. C., W. L. Adamowicz, J. Swait, M. Williams, and J. Louviere. 1996. A comparison of stated preference methods for environmental valuation. Ecological Econ. 18(3): 243-253.

Boyd, J. 2000. Unleashing the Clean Water Act: The promise and challenge of the TMDL approach to water quality. Resources 139(Spring): 7-10.

Carpentier, C. L., D. J. Bosch, and S. S. Batie. 1998. Using spatial information to reduce costs of controlling agricultural nonpoint-source pollution. Agric. and Resource Econ. Review 27(1): 72-84.

Chesapeake Bay Program. 2001. Nutrient trading fundamental principles and guidelines. EPA 903-B-01-001, CBP/TRS 254/01. Annapolis, Md.: U.S. EPA.

Conrad, J. M., and C. W. Clark. 1987. Natural Resource Economics: Notes and Problems. New York, N.Y.: Cambridge University Press.

Crutchfield, S. R., D. Letson, and A. S. Malik. 1994. Feasibility of point-nonpoint source trading for managing agricultural pollutant loadings to coastal waters. Water Resources Res. 30(10): 2825-2836.

Egan, K., J. Herriges, C. Kling, and J. Downing. 2004. Recreation demand using physical measures of water quality. CARD 04-WP 372. Ames, Iowa: Iowa State University, Center for Agricultural and Rural Development.

FARMDOC. 2005. Machinery cost estimates: Tractors. Champaign, Ill.: University of Illinois. Available at: www.farmdoc.uiuc.edu/manage/machinery/machinery_tractors.h tml. Accessed 15 October 2005. 
Feinerman, E., D. J. Bosch, and J. W. Pease. 2004. Manure applications and nutrient standards. American J. Agric. Econ. 86(1): 14-25.

Feng, H., C. Kling, and P. Gassman. 2004. Carbon sequestration, co-benefits, and conservation programs. CARD 04-WP 379. Ames, Iowa: Iowa State University, Center for Agricultural and Rural Development.

Freeman M. A., R. H. Haveman, and A. V. Kneese. 1973. The Economics of Environmental Policy. New York, N.Y.: John Wiley and Sons.

Fuglie, K. O., and D. J. Bosch. 1995. Economic and environmental implications of soil nitrogen testing: A switching-regression analysis. American J. Agric. Econ. 77(4): 891-900.

Gassman, P. W., E. Osei, A. Saleh, and L. M. Hauck. 2002. Application of an environmental and economic modeling system for watershed assessments. J. American Water Resources Assoc. 38(2): 423-438.

Giasson, E., R. B. Bryant, and N. L. Bills. 2002. Environmental and economic optimization of dairy manure management: A mathematical programming approach. Agronomy J. 94(4): 757-766.

Govindasamy, R., M. Cochran, and E. Buchberger. 1994. Economic implications of phosphorus loading policies for pasture land applications of poultry litter. Water Resources Bulletin 30(5): 901-910.

Huang, W. Y. 2005. U.S. fertilizer use and price 1964-2003. Washington, D.C.: USDA Economic Research Service. Available at: www.ers.usda.gov//Data/FertilizerUse/. Accessed 30 June 2005.

Keith, G., S. Norvell, R. Jones, C. Maquire, E. Osei, A. Saleh, P. Gassmen, and J. Rodecap. 2000. Livestock and the environment: A pilot project. TIAER PR003. Stephenville, Texas: Tarleton State University.

Keplinger, K. 2003. The economics of Total Maximum Daily Loads. Natural Resources J. 43(4): 1057-1091.

Krier, J. E., and W. D. Montgomery. 1973. Resource allocation, information cost, and the form of government interventions. Natural Resources J. 13(1): 89-105.

Loomis, J. 2005. Economic values without prices: The importance of nonmarket values and valuation for informing public policy debates. Choices 20(3): 179-182. Ames, Iowa: American Agricultural Economics Association.

Mackenzie, J. 1993. A comparison of contingent preference models. American J. Agric. Econ. 75(3): 593-603.

McCarl, B. A., and T. H. Spreen. 1997. Applied mathematical programming using algebraic systems. College Station, Texas: Texas A\&M University. Available at: http://agecon2.tamu.edu/people/faculty/mccarl-bruce/books.htm. Accessed 22 May 2006.

McNitt, J., R. Jones, E. Osei, L. Hauck, and H. Jones. 1999. Livestock and the environment: Precedents for runoff policy, policy option CEEOT-LP. Report No. PR9909. Stephenville, Texas: Tarleton State University, Texas Institute for Applied Environmental Research.

Miller, W. L., and J. H. Gill. 1976. Equity considerations in controlling nonpoint pollution from agricultural sources. Water Resources Bulletin 12(2): 253-261.

Mitchell, R. C., and R. T. Carson. 1989. Using Surveys to Value Public Goods: The Contingent Valuation Method. Washington, D.C.: Johns Hopkins University Press.

Muñoz-Carpena, R., G. Vellidis, A. Shirmohammadi, and W. W. Wallender. 2006. Modeling tools for TMDL development and implementation. Trans. ASABE 49(4): 961-966.

Musser, W. N., J. S. Shortle, K. Kreahling, B. Roach, W. C. Huang, D. B. Beegle, and R. H. Fox. 1995. An economic analysis of the pre-sidedress nitrogen test for Pennsylvania corn production. Rev. Agric. Econ. 17(1): 25-35.
National Research Council. 2001. Assessing the TMDL Approach to Water Quality Management. Washington, D.C.: National Academy Press.

Ogg, C. 1999. Benefits from managing farm-produced nutrients. $J$. American Water Resources Assoc. 35(5): 1015-1021.

Ogg, C., J. Johnson, and K. Clayton. 1982. A policy option for targeting soil conservation expenditures. J. Soil and Water Cons. 37(2): 68-72.

Osei, E. 2002. Applications of economic simulation models to TMDL analysis. In Proc. 2002 Conference: Total Maximum Daily Load (TMDL) Environmental Regulations, 211-215. St. Joseph, Mich. ASAE.

Osei, E., P. Gassman, and A. Saleh. 2000a. Livestock and the environment: A national pilot project: Economic and environmental modeling using CEEOT. Report No. PR0002. Stephenville, Texas: Tarleton State University, Texas Institute for Applied Environmental Research.

Osei, E., P. Gassman, and A. Saleh. 2000b. Livestock and the environment: A national pilot project: CEEOT-LP modeling for the Upper Maquoketa River Watershed, Iowa: Technical report. Report No. PR0001. Stephenville, Texas: Tarleton State University, Texas Institute for Applied Environmental Research.

Osei, E., P. W. Gassman, R. D. Jones, S. J. Pratt, L. M. Hauck, L. J. Beran, W. D. Rosenthal, and J. R. Williams. 2000c. Economic and environmental impacts of alternative practices on dairy farms in an agricultural watershed. J. Soil Water Conser. 55(4): 466-472.

Osei, E., P. W. Gassman, L. M. Hauck, S. Neitsch, R. D. Jones, J. $\mathrm{McNitt}$, and H. Jones. 2003. Economic and environmental impacts of pasture nutrient management. J. Range Mgmt. 56(3): 218-226.

Portney, P. R. 1998. Counting the cost: The growing role of economics in environmental decisionmaking. Environment 40(March): 14-22.

Pratt, S., R. Jones, and C. A. Jones, 1997. Livestock and the environment: Expanding the focus, policy options CEEOT-LP. Stephenville, Texas: Tarleton State University, Texas Institute for Applied Environmental Research.

Qui, Z., T. Prato, and M. Kaylen. 1998. Watershed scale economic and environmental tradeoffs incorporating risks: A target MOTAD approach. Agric. and Resource Econ. Review 27(2): 231-240.

Qui, Z., T., T. Prato, and F. McCamley. 2001. Evaluating environmental risks using safety-first constraints. American J. Agric. Econ. 83(2): 402-413.

Ribaudo, M. 1989. Water quality benefits from the Conservation Reserve Program. AER 606. Washington, D.C.: USDA Economic Research Service.

Richardson, J. W., and C. J. Nixon. 1981. The farm-level income simulation model: FLIPSIM. Departmental Technical Report (DTR) No. 81-2. College Station, Texas: Texas A\&M University, Department of Agricultural Economics.

Richardson, J. W., P. T. Zimmel, D. P. Anderson, C. A. Moehring, and M. A. Moreno. 1993. Technical description of FLIPSIM operating environment, Version 1.00. Research Report 93-13. College Station, Texas: Texas A\&M University, Agricultural and Food Policy Center.

Robison, L. J., and P. J. Barry. 1987. The Competitive Firm's Response to Risk. New York, N.Y.: Macmillan.

Saleh, A., J. G. Arnold, P. W. Gassman, L. M. Hauck, W. D. Rosenthal, J. R. Williams, and A. M. S. McFarland. 2000. Application of SWAT for the Upper North Bosque River Watershed. Trans. ASAE 43(5): 1077-1087.

Shaw, W. D. 2005. The road less traveled: Revealed preference and using the travel cost model to value environmental changes. Choices 20(3): 183-188. Ames, Iowa: American Agricultural Economics Association.

Shirmohammadi, A., I. Chaubey, R. D. Harmel, D. D. Bosch, R. Muñoz-Carpena, C. Dharmasri, A. Sexton, M. Arabi, M. L. 
Wolfe, J. Frankenberger, C. Graff, and T. M. Sohrabi. 2006. Uncertainty in TMDL models. Trans. ASABE 49(4): 1033-1049.

Smith, V. K. 1993. Nonmarket valuation of environmental resources: An interpretive appraisal. Land Econ. 69(1): 1-26.

Spurlock, S. R., and I. D. Clifton. 1982. Efficiency and equity aspects of nonpoint-source pollution controls. Southern J. Agric. Econ. 14(2): 123-129.

Stevens, T. H. 2005. Can stated preference valuations help improve environmental decision making? Choices 20(3): 189-193. Ames, Iowa: American Agricultural Economics Association.

Teague, M. L, D. J. Bernardo, and H. L. Mapp. 1995. Farm-level economic analysis incorporating stochastic environmental risk. American J. Agric. Econ. 77(1): 8-19.

Tietenberg, T. 2003. Environmental and Natural Resource Economics. 6th ed. New York, N.Y.: Addison Wesley.

U.S. Congress. 1972. Federal Water Pollution Control Act Amendments. P.L. 92-500, 1972.

USDA. Various years. National resources inventory. Washington, D.C.: GPO.

USDA-ERS. 2004. The Conservation Reserve Program: Economic implications for rural America. AER 834. Washington, D.C.: USDA Economic Research Service.

USDA-NRCS. 2005. Highly erodible land and wetland conservation compliance (HELL/WC) provisions. Washington, D.C.: USDA Natural Resources Conservation Service. Available at: www.nrcs.usda.gov/programs/compliance/. Accessed 3 October 2005
USEPA. 1999. Draft guidance for water quality-based decisions: The TMDL process (second edition). Washington, D.C.: U.S. Environmental Protection Agency, Office of Water. Available at: www.epa.gov/owow/tmdl/propguid/Guidance.htm. Accessed 2 August 2005.

USEPA/USDA. 1990. National water quality inventory 1990: Report to Congress. Washington, D.C.: GPO.

Veith, T., M. L. Wolfe, and C. Heatwole. 2003. Optimization procedure for cost-effective BMP placement at a watershed scale. J. American Water Resources Assoc. 39(6): 1331-1343.

Westra, J. V., J. K. Zimmerman, and B. Vondraeck. 2004. Do conservation practices benefit the intended resource concern? Agric. and Resource Econ. Review 33(April): 105-120.

Williams, J. R. 1990. The erosion productivity impact calculator (EPIC) model: A case history. Phil. Trans: Biol. Sci. 329(1255): 421-428.

Williams, J. R. 1995. Chapter 25: The EPIC model. In Computer Models of Watershed Hydrology, 909-1000. V. P. Singh, ed. Highlands Ranch, Colo.: Water Resources Publications.

Williams, J. R., and R. C. Izaurralde. 2006. Chapter 18: The APEX model. In Watershed Models, 437-482. V. P. Singh and D. K. Frevert, eds. New York, N.Y.: CRC Taylor and Francis.

Wu, J. J., and B. A. Babcock. 1999. Metamodeling potential nitrate water pollution in the central United States. J. Environ. Quality 28(6): 1916-1928. 